\title{
Unsere Kinder
}

\section{Samia Hurst}

Dr. med., Institut für Biomedizinische Ethik, Medizinische Fakultät, Genf

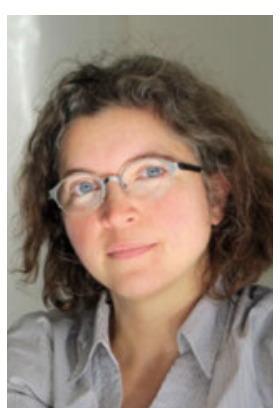

Was heisst das eigentlich, das Kind von jemand oder die Eltern von jemand zu sein? Die Antwort besteht in der Regel aus drei Komponenten.

Erste Komponente: die genetische Abstammung. Unsere Kinder sind genetisch mit uns verwandt. Wir vererben ihnen unsere Merkmale. Darum geht es auch, wenn aussereheliche Kinder ihren "wirklichen Vater» kennenlernen wollen.

Zweite Komponente: die gestationale Abstammung. Das Kind wächst im Körper der Mutter und wird von ihr ausgetragen und ernährt. Der Vater erlebt die Schwangerschaft natürlich anders, aber eben auch als Vater seines Kindes. Genau diese Abstammung macht Probleme bei einer Leihmutterschaft.

Dritte Komponente: die soziale Abstammung. Die Eltern sorgen für die Bedürfnisse des Kindes und für seine Erziehung und Ausbildung. Sie sind verantwortlich für sein Wohlergehen und für die Bedingungen, unter denen seine Entwicklung stattfindet. Sie bringen ihm bei, wie das Leben anzugehen und nach welchen Werten es zu gestalten ist. Sie bilden eine Familie. Wenn die Eltern über Vermögen verfügen, erben die Kinder bei deren Ableben. Darum geht es bei der Adoption.

Meist kommen diese verschiedenen Komponenten der Abstammung parallel bei denselben Personen vor. Ist dies nicht der Fall, sind wir irritiert. Die Leihmutterschaft - sie wird in dieser Ausgabe unter einem "theologisch-ethischen» Blickwinkel betrachtet - zählt zu jenen Fällen, die Unbehagen verursachen.

\section{Seine Herkunft kennen ist Teil unserer Identitätsbildung.}

Dieses Unbehagen hemmt unser Handeln. Die Adoption trennt die Abstammungen und verursacht dasselbe Unbehagen. «Haben Sie Kinder, ich meine, eigene Kinder?» Die Trennung der Abstammungen stört uns. Dennoch käme niemand auf die Idee, die Adoption zu verbieten. Wo also liegt das eigentliche Problem? Die von Frau Dr. Schliesser in ihrem Artikel diskutierten Fälle regen zum Nachdenken an. Einige - darunter die Versteigerung eines Neugeborenen - schockieren, sind jedoch bereits durch die bestehende Gesetzgebung verboten. Was uns bei den anderen Fällen stört, ist das Risiko, dass die Kinder nichts über ihre Herkunft erfahren, oder dass die Eltern ihrer Pflicht nicht nachkommen oder dass die Kinder oder Eltern ausgebeutet werden.

Seine Herkunft kennen ist Teil unserer Identitätsbildung. Daher hat der Schweizer Gesetzgeber das Recht auf Kenntnis der Herkunft garantiert. Wir verbieten eine anonyme Samenspende. Auch die anonyme Geburt ist verboten. Folgen wir dieser Logik, dann müsste auch bei der Leihmutterschaft das Recht auf Kenntnis der Leihmutter gegeben sein. Unbehagen? Sicherlich! Gerade darum wäre dies ein interessanter Schutzmechanismus. Käme das Kind von einer Leihmutter, die in schlecht geschützten Ländern ausgebeutet wird, so würde dies später sicherlich schwierige Diskussio-

\section{Daher hat der Schweizer Gesetzgeber das Recht} auf Kenntnis der Herkunft garantiert.

nen mit dem betreffenden Kind nach sich ziehen. In Ländern, in denen freiwillige Leihmütter besser geschützt sind, besteht die Hoffnung dieser Mütter oft darin, nach der Geburt von der neuen Familie nicht vollkommen vergessen zu werden.

Ein Elternteil, der sein Kind verlässt, unabhängig davon, ob es mit oder ohne Hilfe der Medizin zur Welt kam, ja, das ist ein Problem. In Bezug auf das Kind, aber auch in Bezug auf die anderen Eltern. Wenn man Eltern wird durch die Hilfe der Leihmutterschaft, muss diese Rolle auch ernst genommen werden. Es bestehen dieselben Pflichten wie bei anderen Eltern auch. Natürlich gibt es Eltern, die ihren Pflichten nicht nachkommen oder die versuchen, anderen Eltern unzulässige Bedingungen zu stellen. Diese Problematik gibt es bereits viel länger als die medizinisch unterstützte Fortpflanzung oder die Leihmutterschaft. Wir müssen hier von denselben Voraussetzungen ausgehen können.

Diese Massnahmen sind nicht a priori unmöglich. Sie lassen sich daher nicht so eindeutig als Grundlage für ein Leihmutterschaftsverbot heranziehen. Sie konfrontieren uns allerdings mit Fragen, die wir lieber gar nicht als existent ansehen würden. Und das - ja das ist unbequem ... 